\title{
Modeling of Flocculation and Sedimentation Using Population Balance Equation
}

\author{
Zhipeng Shi $\mathbb{i},{ }^{1,2,3}$ Genguang Zhang $\mathbb{D}^{1,3}$ Yuzhuo Zhang, ${ }^{1}$ Tingting He, $^{2}$ and Guoliang Pei ${ }^{4}$ \\ ${ }^{1}$ Key Laboratory of Agricultural Soil and Water Engineering in Arid and Semiarid Areas, Ministry of Education, \\ Northwest A\&F University, Yangling, Xianyang, Shaanxi Province 712100, China \\ ${ }^{2}$ Jiangsu Vocational Institute of Architectural Technology, Xuzhou, Jiangsu Province 221116, China \\ ${ }^{3}$ College of Water Resources and Architectural Engineering, Northwest A\&F University, Yangling, Xianyang, \\ Shaanxi Province 712100, China \\ ${ }^{4}$ State Key Laboratory of Crop Stress Biology for Arid Areas, Northwest A\&F University, Yangling, Xianyang, \\ Shaanxi Province 712100, China \\ Correspondence should be addressed to Genguang Zhang; zgg64@163.com
}

Received 1 June 2019; Revised 19 July 2019; Accepted 12 September 2019; Published 26 September 2019

Guest Editor: Chenglian Feng

Copyright (c) 2019 Zhipeng Shi et al. This is an open access article distributed under the Creative Commons Attribution License, which permits unrestricted use, distribution, and reproduction in any medium, provided the original work is properly cited.

\begin{abstract}
Flocculation is a special phenomenon for fine sediment or silt in reservoirs and estuaries. Flocculation usually results in changes of size, morphology, and settling velocity of sediment particles and finally changes of bed topography of reservoirs and estuaries. The process of flocculation and sedimentation was simulated based on population balance modeling (PBM) and computational fluid dynamics (CFD); the changes of particle or floc size and their settling velocities over time were examined. The results showed that flocculation is a dynamic and nonlinear process containing aggregation, breakage, reaggregation, and rebreakage between particles, microflocs, and macroflocs. Furthermore, the visual process of flocculation and sedimentation was directly created by the simulation results and is in good agreement with the results of the previous experiments.
\end{abstract}

\section{Introduction}

Flocculation (floc) of fine sediments is a research focus in the theory of sediment movement mechanics. Many phenomena of the settling velocity of sediment, such as sediment topography of the estuary (sediment barrier), the formation of non-Newtonian fluid, huge sediment-carrying capacity, and pulp rivers, are related to the flocculation of fine sediment $[1,2]$. Flocculation has often been observed in marine and estuarine environments as well [3]. Experimental studies on the characteristics of floc and their influencing factors were conducted by many researchers, and a series of results were achieved [4-6]. In this study, we mainly investigate the mathematical modeling of flocculation and sedimentation in three dimensions.

The mathematical model of flocculation came into focus, when Witten and Sander [7] first established the diffusionlimited aggregation (DLA) model. The growth process of floc was simulated using the DLA model in a 2D space, and three methods for calculating the fractal dimension of floc were compared by Jin et al. [8]. Qin et al. [9] developed a 3D model for the growth of floc using the DLA model as a base. The fractal dimensions of 3D DLA aggregates are higher than those of 2D DLA aggregates, according to Liu et al. [10]. However, the DLA model assumes that there is a stationary particle within the central, which is far from the actual situation. Then, Meakin [11] improved the model and proposed a diffusion-limited cluster-cluster aggregation (DLCCA) model. Gimel et al. [12] studied the process of solgel transition with the DLCCA by Monte Carlo simulation. Zhang and Zhang [13] found the drag forces on flocs formed by DLCCA are larger than those formed by DLA. However, there still are two assumptions of the above model that need to be improved. First, the particle is limited to a uniform sphere; second, the process of breakage is always neglected resulting in large deviations with reality. The population 
balance model (PBM) [14-17], consisting of aggregation and breakage mechanisms, successfully solved the assumptions mentioned above $[18,19]$. Due to the theory of collision frequency and collision efficiency, the process of aggregation and breakage can be better reflected in the PBM [20].

The aim of this study is to apply the PBM to the flocculation and sedimentation process in three dimensions. PBM was incorporated into the computational fluid dynamics (CFD) model by implementing the multiple size group model. The CFD-PBM combination is an effective method to solve the processes of flocculation and multiphase flow simultaneously [21]. In this study, the process of flocculation and sedimentation and characteristics of flocs across different time periods with validation are presented using experimental data from the literature.

\section{Model Description and Methods}

2.1. CFD Implementation. The process of flocculation and sedimentation is the process of a typical solid-liquid two- phase flow interaction. Therefore, the Euler-Euler model was employed within the flocculating system [22].

\subsubsection{Continuity Equation.}

$$
\frac{\partial}{\partial t}\left(\alpha_{q} \rho_{q}\right)+\nabla \cdot\left(\alpha_{q} \rho_{q} \vec{v}_{q}\right)=\sum_{p=1}^{n}\left(\dot{m}_{p q}-\dot{m}_{q p}\right)+S_{q},
$$

where $\nabla$ is the Hamiltonian; $S_{q}$ is the source item; $\alpha_{q}$ and $\rho_{q}$ are the volume fraction and density of phase $q$, respectively; $p$ and $q$ represent different phases; $\vec{v}_{q}$ is the velocity of phase $q$; and $\dot{m}_{p q}$ and $\dot{m}_{q p}$ characterize the mass transfer within the different phases. The source term $S_{q}$ on the righthand side of equation (1) is zero by default.

2.1.2. Momentum Equation. The momentum balance for phase $q$ yields:

$$
\begin{aligned}
\frac{\partial}{\partial t}\left(\alpha_{q} \rho_{q} \vec{v}_{q}\right)+\nabla \cdot\left(\alpha_{q} \rho_{q} \vec{v}_{q} \vec{v}_{q}\right)= & -\alpha_{q} \nabla \cdot P+\nabla \cdot \overline{\bar{\tau}}_{q}+\alpha_{q} \rho_{q} \vec{g} \\
& +\sum_{p=1}^{n}\left(\vec{R}_{p q}+\dot{m}_{p q} \vec{v}_{p q}-\dot{m}_{q p} \vec{v}_{q p}\right)+\left(\vec{F}_{q}+\vec{F}_{\mathrm{lift}, q}+\vec{F}_{\mathrm{wl}, q}+\vec{F}_{\mathrm{vm}, q}+\vec{F}_{\mathrm{td} . q}\right)
\end{aligned}
$$

where $\overline{\bar{\tau}}_{q}$ is the $q^{\text {th }}$ phase stress-strain tensor and $\vec{g}$ is the gravity acceleration.

$$
\overline{\bar{\tau}}_{q}=\alpha_{q} \mu_{q}\left(\nabla \vec{v}_{q}+\nabla \vec{v}_{q}^{T}\right)+\alpha_{q}\left(\lambda_{q}-\frac{2}{3} \mu_{q}\right) \nabla \cdot \vec{v}_{q} \overline{\bar{I}}
$$

where $\mu_{q}$ and $\lambda_{q}$ are the shear and bulk viscosity of phase $q$, $\vec{F}_{q}$ is an external body force, $\vec{F}_{\text {lift, } q}$ is a lift force, $\vec{F}_{\mathrm{wl}, q}$ is a wall lubrication force, $\vec{F}_{\text {vm, } q}$ is a virtual mass force, and $\vec{F}_{\text {td. } q}$ is a turbulent dispersion force (in the case of turbulent flows only). $\vec{R}_{p q}$ is an interaction force between phases, and $p$ is the pressure shared by all phases. Finally, $\vec{v}_{p q}$ is the interphase velocity.

2.1.3. Turbulence Modeling. A standard $k-\varepsilon$ turbulence model was employed because it reduces the computational effort and increases the reasonable accuracy of the model $[23,24]$.

$$
\begin{aligned}
& \frac{\partial}{\partial t}(\rho k)+\frac{\partial}{\partial x_{i}}\left(\rho k u_{i}\right)=\frac{\partial}{\partial x_{j}}\left[\left(\mu+\frac{\mu_{t}}{\sigma_{k}}\right) \frac{\partial k}{\partial x_{j}}\right]+G_{k}+G_{\mathrm{b}}-\rho \varepsilon-Y_{\mathrm{M}}+S_{q} \\
& \frac{\partial}{\partial t}(\rho \varepsilon)+\frac{\partial}{\partial x_{i}}\left(\rho \varepsilon u_{i}\right)=\frac{\partial}{\partial x_{j}}\left[\left(\mu+\frac{\mu_{t}}{\sigma_{\varepsilon}}\right) \frac{\partial \varepsilon}{\partial x_{j}}\right]+C_{1 \varepsilon} \frac{\varepsilon}{k}\left(G_{k}+C_{3 \varepsilon} G_{\mathrm{b}}\right)-C_{2 \varepsilon} \rho \frac{\varepsilon^{2}}{k}+S_{q}
\end{aligned}
$$

In these equations, $k$ is the turbulence kinetic energy; $\varepsilon$ is the turbulent energy dissipation rate; and $G_{k}$ represents the generation of turbulence kinetic energy due to the mean velocity gradients. $G_{\mathrm{b}}$ is the generation of turbulence kinetic energy due to buoyancy. $Y_{M}$ represents the contribution of the fluctuating dilatation in compressible turbulence to the overall dissipation rate. $C_{1 \varepsilon}, C_{2 \varepsilon}$, and $C_{3 \varepsilon}$ are constants. $\sigma_{k}$ and $\sigma_{\varepsilon}$ are the turbulent Prandtl numbers for $k$ and $\varepsilon$, respectively. $S_{q}$ is the user-defined source term.

2.2. Population Balance Model. Assuming that $\phi$ is the particle volume, the transport equation for the number density function is given as 


$$
\begin{aligned}
\frac{\partial}{\partial t} & {[n(V, t)]+\nabla \cdot[\vec{u} n(V, t)]+\underbrace{\nabla_{v} \cdot\left[G_{v} n(V, t)\right]}_{\text {grown term }} } \\
= & \underbrace{\frac{1}{2} \int_{0} \alpha\left(V-V^{\prime}, V^{\prime}\right) n\left(V-V^{\prime}, t\right) n\left(V^{\prime}, t\right) d V^{\prime}}_{\text {birth due to aggregation }}-\underbrace{\int_{0}^{\infty} \alpha\left(V, V^{\prime}\right) n(V, t) n\left(V^{\prime}, t\right) d V^{\prime}}_{\text {death due to aggregation }}+\underbrace{\int_{\text {birth due to breakage }} p g\left(V^{\prime}\right) \beta\left(V \mid V^{\prime}\right) n\left(V^{\prime}, t\right) d V^{\prime}}_{\Omega_{v}} \\
& -\underbrace{g(V) n(V, t)}_{\text {death due to breakage }},
\end{aligned}
$$

where $n(V, t)$ is the number density of particles of volume $V$ at time $t ; \nabla$ is the Hamiltonian; $\vec{u}$ is the particle velocity; $G$ is the linear growth rate; and $G=\partial L / \partial t ; B_{\mathrm{ag}}, D_{\mathrm{ag}}, B_{\mathrm{br}}, D_{\mathrm{br}}$ represent the birth and death rates due to aggregation and breakage respectively $[25,26]$. They are given as [27]

$$
\begin{aligned}
& B_{\mathrm{ag}}=\frac{1}{2} \int_{o}^{V} \alpha\left(V-V^{\prime}, V^{\prime}\right) n\left(V-V^{\prime}\right) n\left(V^{\prime}\right) d V^{\prime}, \\
& D_{\mathrm{ag}}=\int_{o}^{\infty} \alpha\left(V, V^{\prime}\right) n(V) n\left(V^{\prime}\right) d V^{\prime}, \\
& B_{\mathrm{br}}=\int_{\Omega_{v}} N g\left(V^{\prime}\right) \beta\left(V \mid V^{\prime}\right) n\left(V^{\prime}\right) d V^{\prime}, \\
& D_{\mathrm{br}}=g(V) n(V),
\end{aligned}
$$

where particles of volume $V-V^{\prime}$ aggregate with particles of volume $V^{\prime}$ to form particles of volume $V$. The factor $1 / 2$ is included to avoid accounting for each collision event twice. $g\left(V^{\prime}\right) n\left(V^{\prime}\right) d V^{\prime}$ particles of volume $V^{\prime}$ break per unit time, producing $p g\left(V^{\prime}\right) n\left(V^{\prime}\right) d V^{\prime}$ particles, of which a fraction $\beta\left(V \mid V^{\prime}\right) d V$ represent particles of volume $V . N$ is the number of child particles produced per parent particle.

The Luo and Ghadiri models were adopted to study the aggregation and breakage processes between particles, respectively [28].

2.3. Experimental. Flocculation and sedimentation experiments were performed on particles diluted to $5 \mathrm{~g} / \mathrm{L}$ and $15 \mathrm{~g} / \mathrm{L}$ solid in deionized water in a $1000 \mathrm{ml}$ graduated cylinder. Particles, with a mean diameter of $39.63 \mu \mathrm{m}$, were used as the model suspension. They were obtained from Luohe aqueduct in the Yellow River. Deionized (DI) water with a $\mathrm{pH}$ of 7.1 was employed for all experimental work. All experiments were carried out in two steps. First, particles were dispersed by vigorous stirring at $200 \mathrm{rpm}$ for 3 minutes to prepare the suspensions, followed by 5 minutes of slow stirring. The settling velocity of floc was recorded during the process. The settling velocity was calculated using the distance traveled by a floc and the travel time measured by a digital-display stopwatch. Second, the floc suspension was transferred to glass slides with a pipet ( $8 \mathrm{~mm}$ inner diameter mouth) and then freeze-dried. Finally, images of the flocs were captured by a microscope imaging system and analyzed by the Image pro Plus 6.0 software; this is how the size of the floc was measured. The detailed results for the flocculation and sedimentation experiments are presented previously [29].

2.4. Numerical Details. The Ansys Fluent 15.0 software was used to solve the equations of mass, momentum, and population balance equations. Considering that the previous experiment of flocculation and sedimentation were carried out in a $1000 \mathrm{ml}$ graduated cylinder, the three-dimensional geometry of this cylinder was built with a $0.068 \mathrm{~m}$ diameter and $0.44 \mathrm{~m}$ height. The details of the experimental data can be found in the cited references [29]. Meshing was implemented using a structural mesh of $0.04 \mathrm{~mm}$ grid sizes. The total number of nodes is 1,642,170. Figure 1 shows the geometry with the mesh.

Water was chosen as the growth medium liquid phase. Considering the range of the initial particle diameter, the solid dispersed phase was divided into 6 groups (Table 1). Each group was considered as having an individual percentage. The floc was formed by collision within particles, along with the interaction of the velocity and flow fields. A coupled solver was used to solve the momentum and pressure items. A second-order backward scheme was adopted for temporal discretization. The convergence criteria were set to 0.0001 for all variables. Based on the previous experiment, the boundary conditions of the inlet were defined as the velocity inlet, and other parts were defined as the wall. All procedures explained were conducted by using the Ansys Fluent 15.0 software package [24].

\section{Results and Discussion}

3.1. Flocculation and Sedimentation. The critical size of flocculation between particles is $0.01 \sim 0.03 \mathrm{~mm}$ for different water quality and particle properties [30]. The specific value should be determined by the local environment conditions. For example, in estuary coastal areas, when fine sediment particles occupy a large proportion, even if the particle size is greater than $0.03 \mathrm{~mm}$, we should consider the influence of flocculation. Two conditions must be met for flocculation: first, there must be a certain collision frequency during the process; second, the collision efficiency is also very important. Brownian motion, applied shear and differential sedimentation are three mechanisms for the collisions. The process of flocculation and sedimentation between particles or flocs is shown in Figure 2 .

The phenomenon of aggregation and breakage can be clearly observed during the process of flocculation and sedimentation, as shown in Figure 2. For example, the aggregation of particles is more clearly reflected in the images 


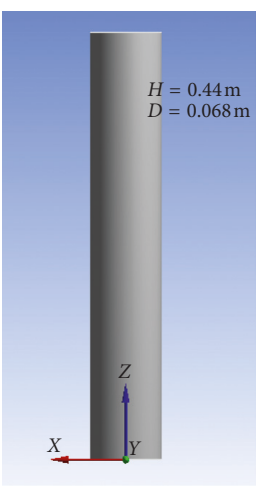

(a)

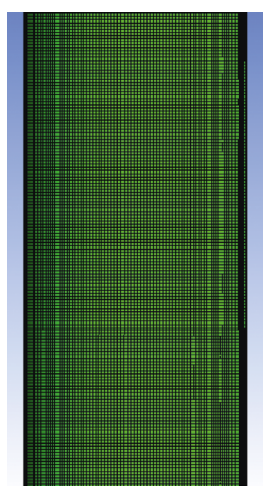

(b)

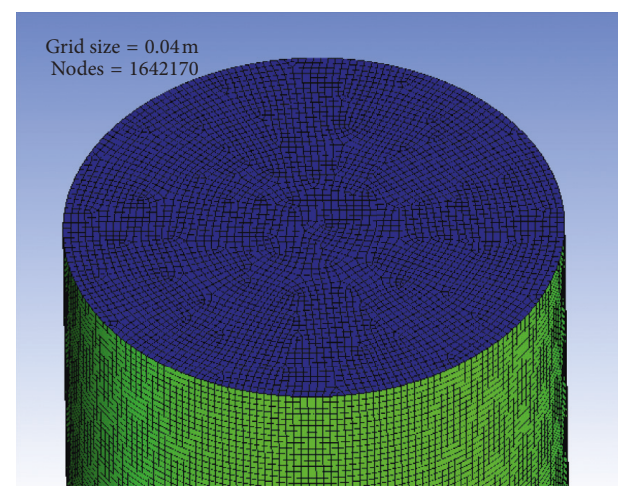

(c)

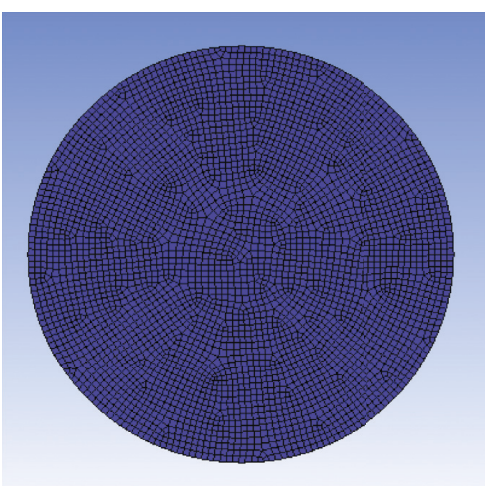

(d)

Figure 1: Three-dimensional geometry and grid measurements with meshing. (a) geometry; (b) $\times 20$ times; (c) $\times 40$ times; (d) $\times 30$ times.

TABle 1: Particle size groups.

\begin{tabular}{lcccccc}
\hline No. & Bin 0 & Bin 1 & Bin 2 & Bin 3 & Bin 4 & Bin 5 \\
\hline Size $\left(\times 10^{-3} \mathrm{~m}\right)\left(d_{50}\right)$ & 0.031 & 0.032 & 0.038 & 0.026 & 0.007 & 0.021 \\
$\begin{array}{l}\text { Volume concentration } \\
(\%)\end{array}$ & 10 & 20 & 20 & 20 & 20 & 10 \\
\hline
\end{tabular}

of $T=5 \mathrm{~s}$ and $T=10 \mathrm{~s}$. The particle size and number of flocs increase significantly. Breakage of macroflocs is also more clearly reflected from the image of $T=30 \mathrm{~s}$. This is the result of effective collisions between the particles. There are three different states during the flocculation and sedimentation process: particles, microflocs, and macroflocs. According to Manning and Dyer [31], $0.16 \mathrm{~mm}$ is the critical size of microflocs and macroflocs. Although they have three different states, they are not fixed. The process of flocculation and sedimentation is a dynamic and nonlinear process of aggregation, breakage, reaggregation and rebreakage.

It can also be seen from Figure 2 that aggregation takes place as a result of particle-particle, particle-microflocs, or microflocs-microflocs collisions, leading to the formation of macroflocs. Additionally, the flocs are all highly irregular in shape and structure. Lee et al. [32] believe that there are four typical processes of flocculation in two-class PBM: (1) aggregation between microflocs, (2) aggregation between microflocs and macroflocs, (3) aggregation between macroflocs, and (4) breakage of macroflocs. Gregory and Zabel [33] also conceived the morphology of flocs during sedimentation, and compared to their regimes, the calculation results of flocculation and sedimentation in Figure 2 are indeed correct.

3.2. Particle or Floc Size. The time series of the particle or floc size during flocculation and sedimentation is predicted with CFD-PBM, as shown in Figure 3. It can be observed from Figure 3 that the size profiles of the particles or flocs initially decrease and then increase, especially for the first three Bins (Bin $0 \sim \operatorname{Bin} 2$ ). The reason is that there were a large number of particles with a high collision frequency in the first $10 \mathrm{~s}$ resulting in a large shearing effect. However, as the collision frequency increased, the collision efficiency also gradually increased. Then after $10 \mathrm{~s}$, the floc size began to increase. Around $15 \mathrm{~s}$, the curves show a maximum point. Microflocs gradually appeared. The stage of $15 \sim 24 \mathrm{~s}$ is a relatively stable stage. Relative to the initial phase, the size increased significantly. However, after $24 \mathrm{~s}$, the curve increased dramatically, indicating that macroflocs gradually appeared. The volume of macroflocs is larger than that of a sphere because macroflocs usually have an irregular and porous structure [34]. Combined with Figure 2, the process of flocculation and sedimentation can be summarized into three stages: first, $0 \sim 15 \mathrm{~s}$, which is primarily the interaction between particles; second, 15 24 s, which is primarily the interaction between microflocs; third, 24 30 s, which is primarily the interaction between macroflocs. The photos and size of the flocs as shown in Figure 4 were obtained based on the previous experiments, which were measured using a research grade microscope imaging system (UHGLGPS, OLYMPUS company, Japan) and Image Pro Plus 6.0 software. Particles, microflocs, and macroflocs are three different states with a huge difference in size. The average and maximum size of flocs in the experiments were $174.84 \mu \mathrm{m}$ and $364.49 \mu \mathrm{m}$, respectively, which may correspond to the size of microflocs and macroflocs. Additionally, the size of flocs in the model described quite well with the variation of the experimental flocs size. It is confirmed that the proposed model offers a good approximation for the flocculation and sedimentation.

The collision frequency between particles can result from Brownian motions, shear flow, or differential settling [35]. In this study, the shear flow and differential settling are the main causes of particle or floc collision. Vajihinejad and Soares [34] observed the same trend as in Figure 3. They believed that there is a dispersal time for particles or polymer within the suspension before flocculation occurs. After that time, they grow quickly to a maximum value, and then reach an equilibrium stage [36]. Heath et al. [37] believed that the size decrease was caused by polymer degradation. From the results of this study, we believe that this phenomenon can be explained by shear effect and differential settling. Shear effect focuses on the early stage, while differential settling influences the later stage. In addition, an increase of the curve results from the aggregation of particles or flocs, while the fluctuation of the curve is a symbol of equilibrium. During the equilibrium stage (fluctuation stage between $25 \mathrm{~s} \sim 30 \mathrm{~s}$ ), 


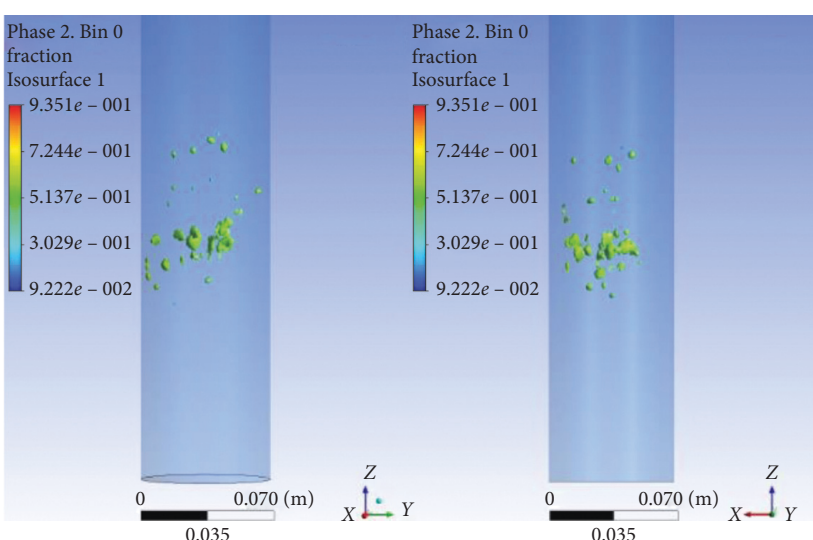

(a)

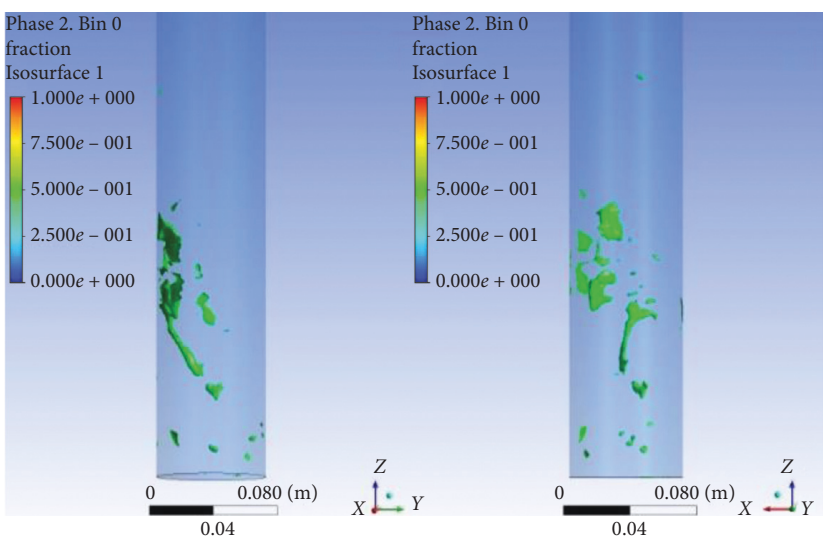

(c)

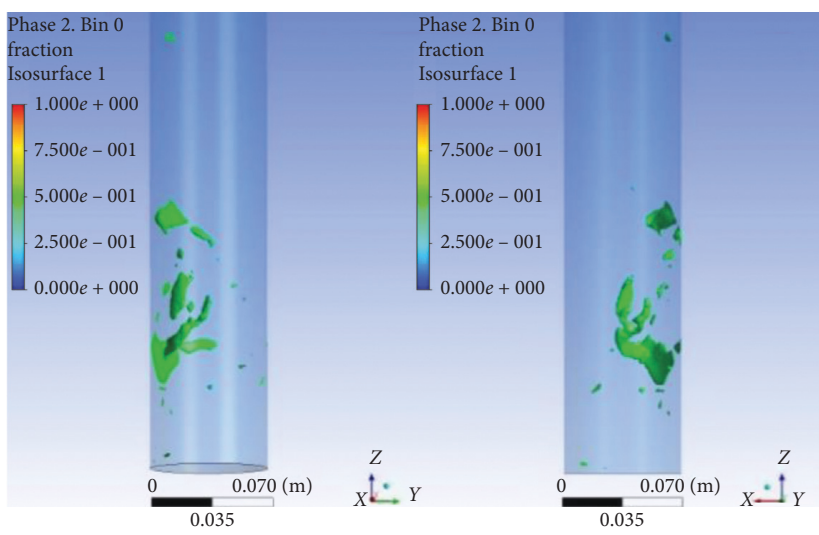

(e)

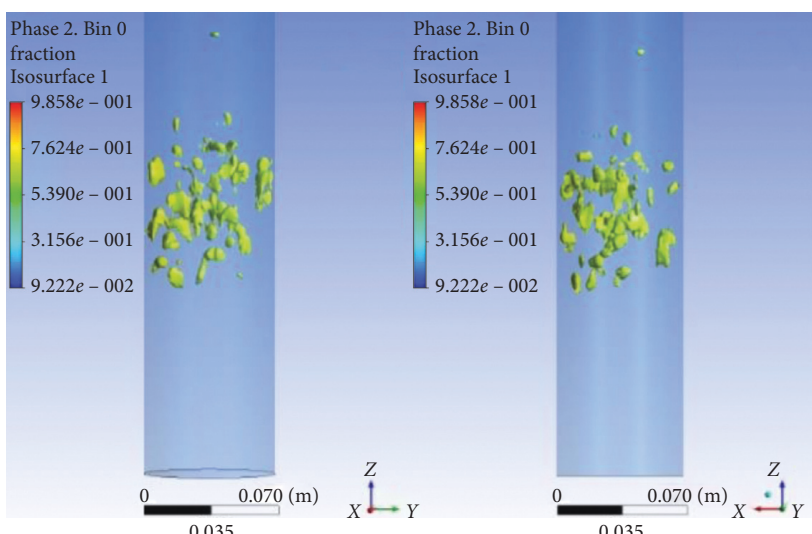

(b)

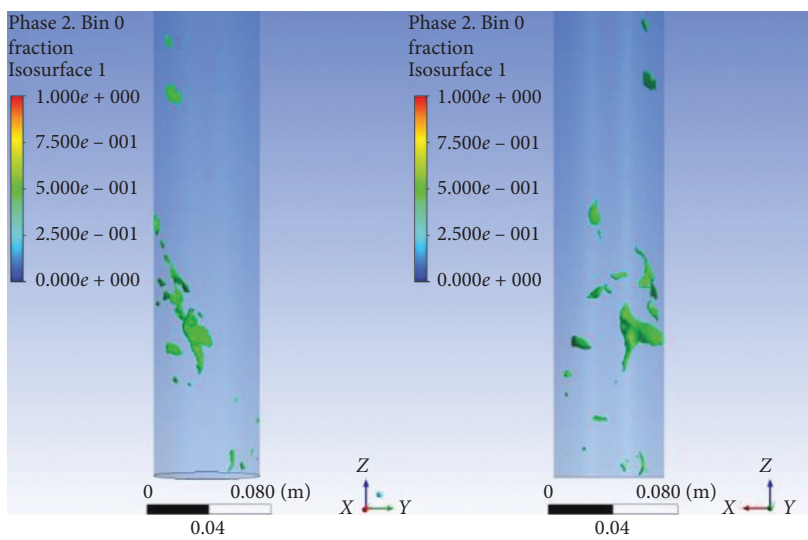

(d)

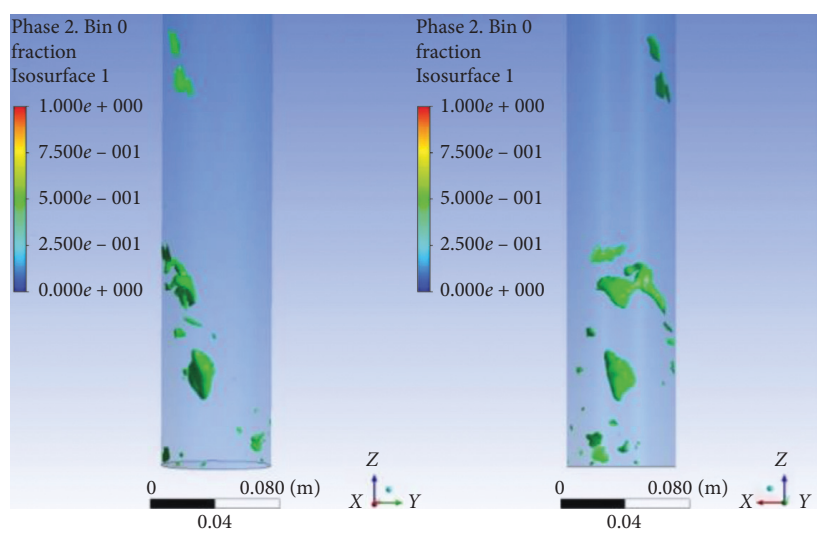

(f)

FIGURE 2: The process of flocculation and sedimentation between particles or flocs. Note that (a) and (b) represent the process of flocculation and sedimentation between particles at $5 \mathrm{~s}$ and $10 \mathrm{~s}$, respectively. Images $(\mathrm{c})$ and $(\mathrm{d})$ represent the process of flocculation and sedimentation between microflocs at $15 \mathrm{~s}$ and $20 \mathrm{~s}$, respectively. Finally, (e) and (f) represent the process of flocculation and sedimentation between macroflocs at $25 \mathrm{~s}$ and $30 \mathrm{~s}$, respectively. (a) Time $=5 \mathrm{~s}$ (particles). (b) Time $=10 \mathrm{~s}$ (particles). (c) Time $=15 \mathrm{~s}$ (microflocs). (d) Time $=20 \mathrm{~s}$ (microflocs). (e) Time $=25 \mathrm{~s}$ (macroflocs). (f) Time $=30 \mathrm{~s}$ (macroflocs).

although both aggregation and breakage occurred, their effects were neutralized within one another.

3.3. Particle or Floc Settling Velocity. The settling velocity is a key parameter in modeling the settlement process in sedimentation analysis and sediment transport. For noncohesive particles, the settling velocity is dependent on the individual particle size, gravity, and particle shape, which substantially differs from the settling velocity of floc. For example, due to the process of flocculation, muds are often changed to flocs during suspension in estuary coastal areas [38]. For such flocs, the size, shape, and settling velocity all become a dynamic process. Therefore, it is necessary to know the 


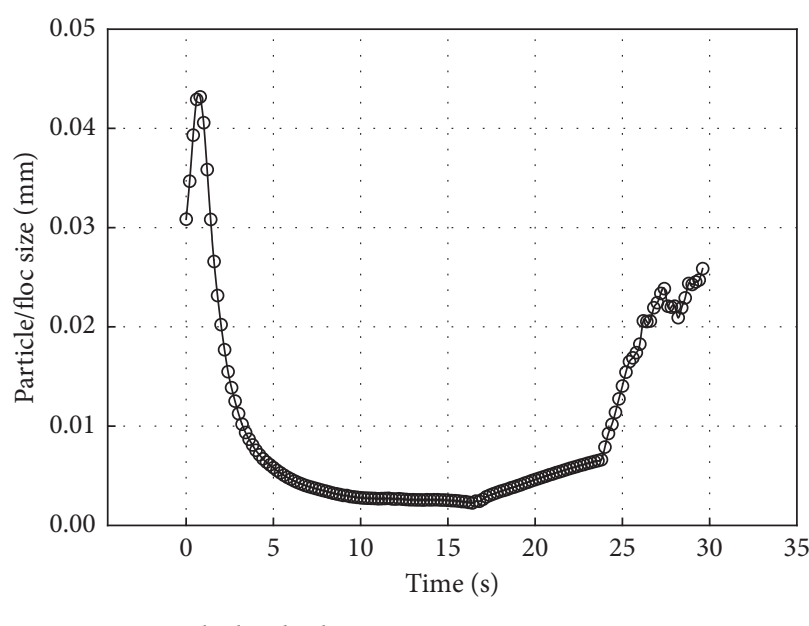

(a)

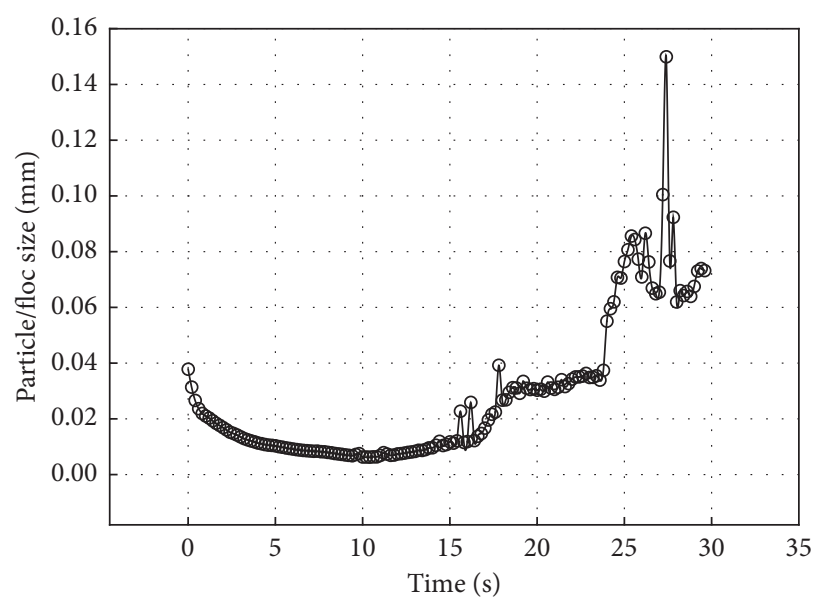

- $\_$Calculated value 3

(c)

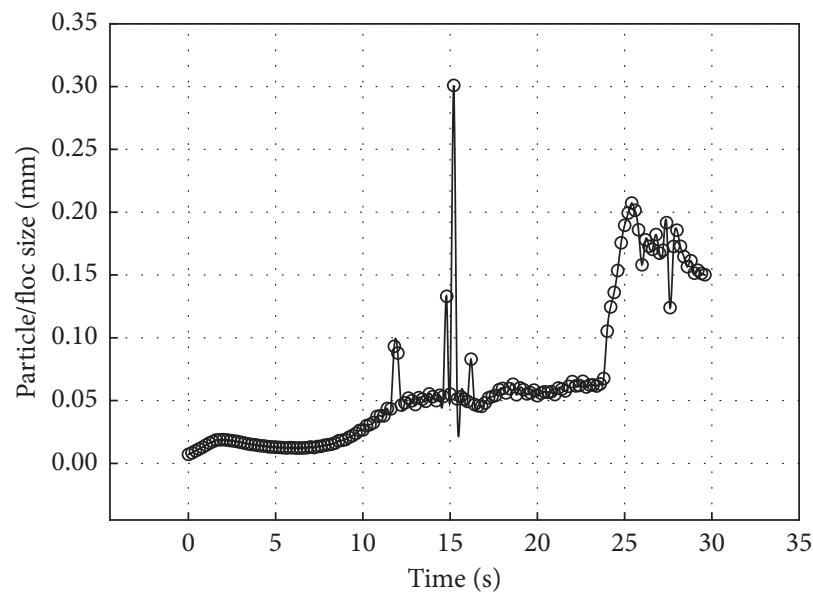

- Calculated value 5

(e)

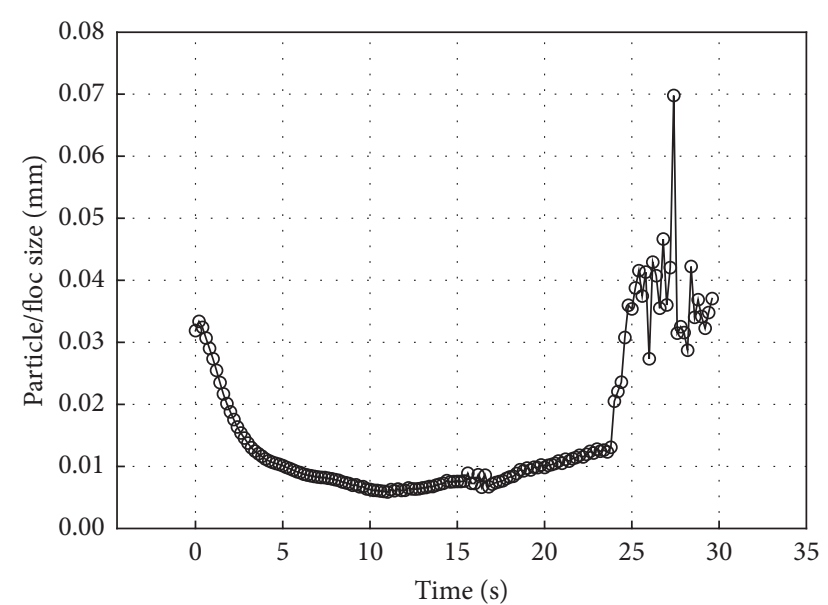

- Calculated value 2

(b)

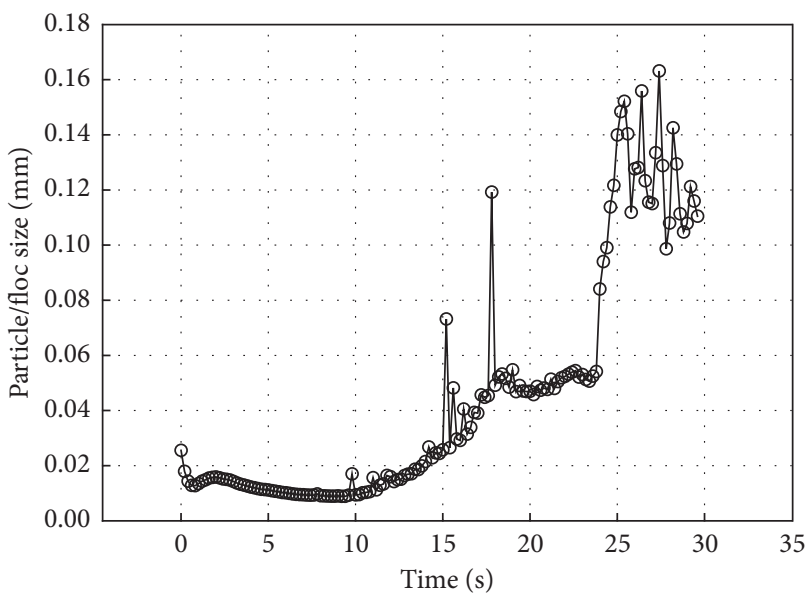

- Calculated value 4

(d)

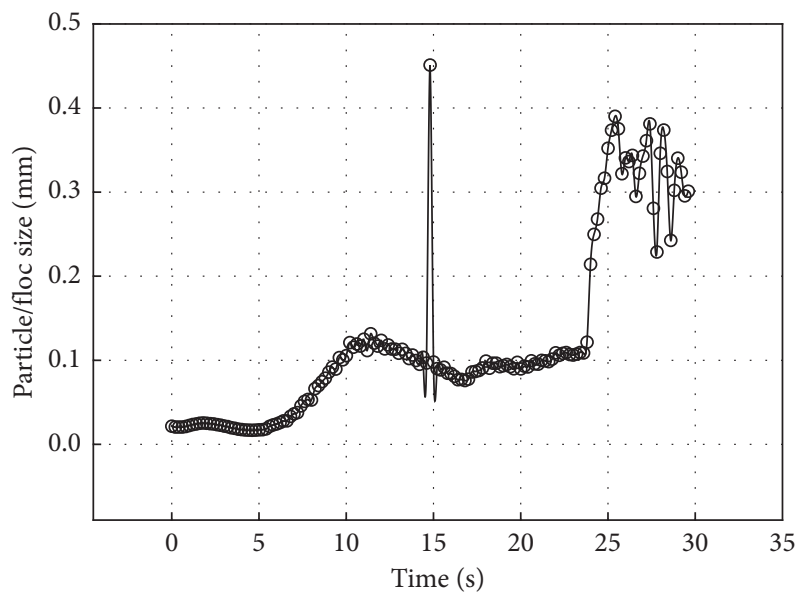

(f)

Figure 3: Time series of the particle or floc size of each bin: (a) Bin 0. (b) Bin 1. (c) Bin 2. (d) Bin 3. (e) Bin 4. (f) Bin 5. 


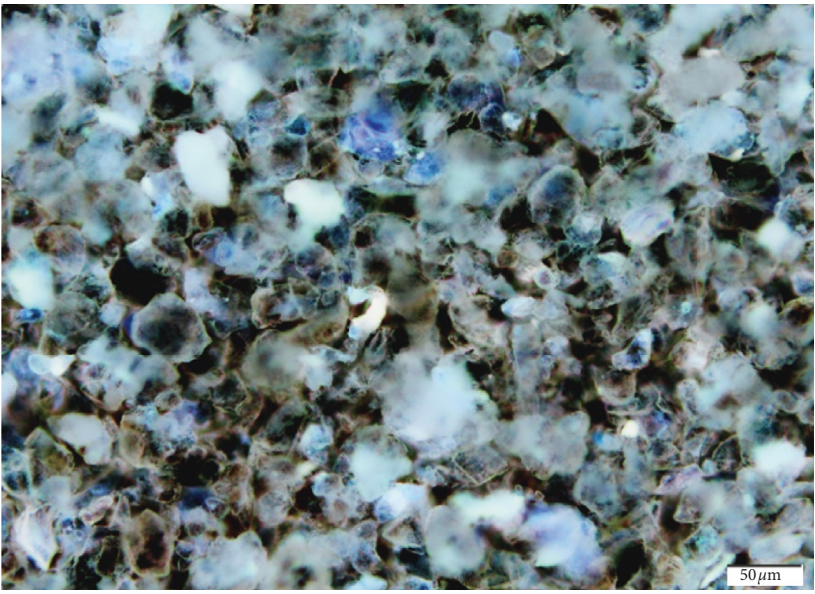

(a)

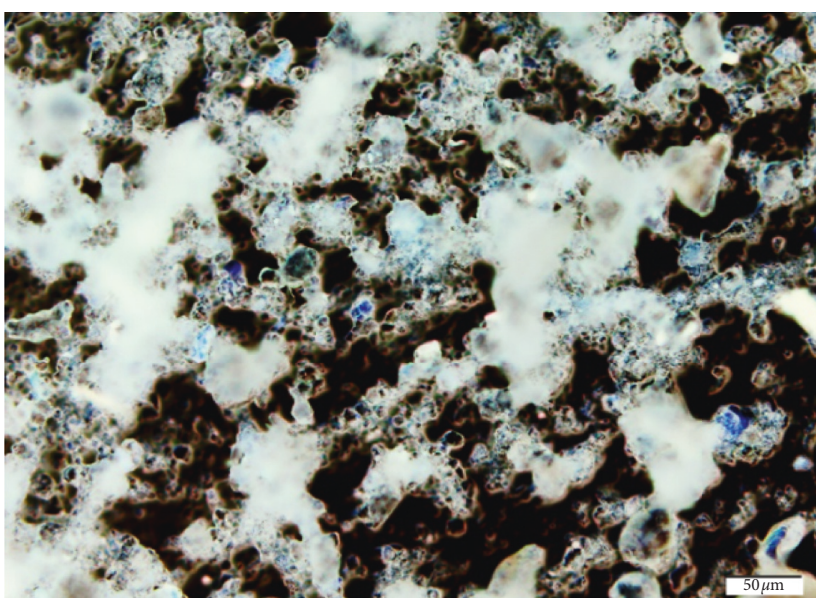

(c)

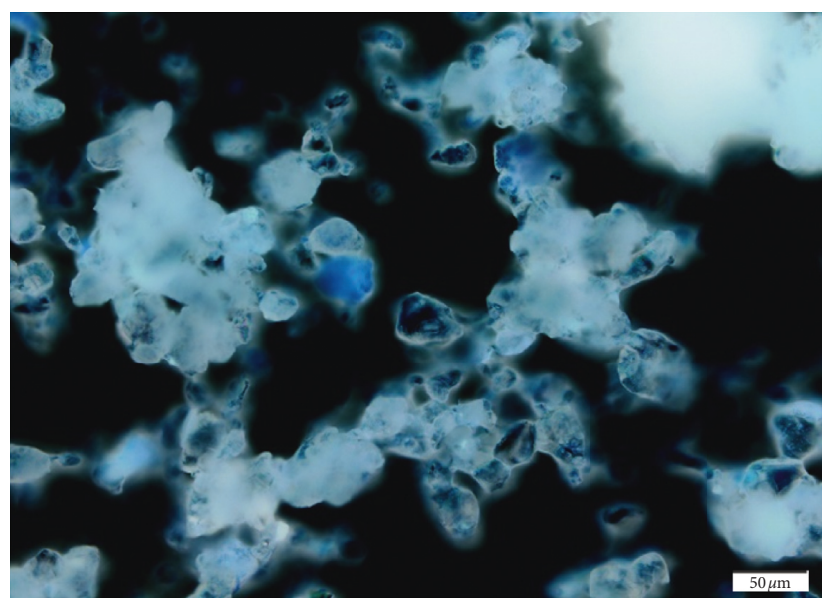

(b)

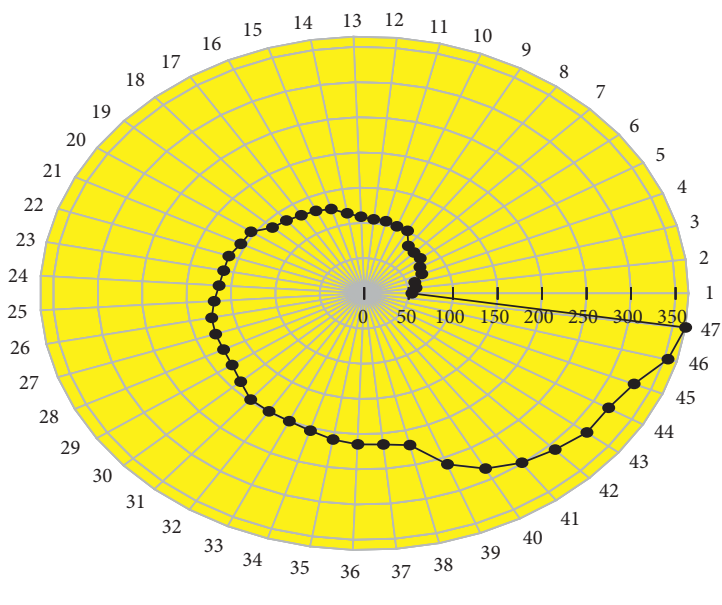

(d)

Figure 4: Three states and sizes of flocs during flocculation and sedimentation in experiments: (a) Particles. (b) Microflocs. (c) Macroflocs. (d) Size in experiments $(\mu \mathrm{m})$.

dynamic treatment of the settling velocity in order to more accurately evaluate and predict the sediment transport processes. However, most of the research on this topic is mainly concerned with the relationship between the floc settling velocity and its size, while there remain only a few studies on the time series of the floc settling velocity. We examined the differences in settling velocity functionality with time and the differences of settling velocities in different directions, as shown in Figure 5. Note that $N=33$ in Figure 5 means the total number of settling velocities obtained from the experiments is 33 .

It should be noted that from Figure 5, the curve of the settling velocity decreased in $0 \sim 15 \mathrm{~s}$ and then increased in 15 30 s regardless of the direction. The main reason for this phenomenon is that the collision frequency was higher at the beginning, resulting in a large shear effect. Due to the shearing effect, the floc began to experience breakage, resulting in decreasing size. Another reason is that there is a resistance effect from the particles on the lower position to the particles on the upper position. Li et al. [39] believe that a rigid network was formed by aggregated particles, resulting in a sharp decrease of the settling velocity. As mentioned above, after $15 \mathrm{~s}$, the collision efficiency increased. The effect of aggregation was more powerful than the effect of breakage, resulting in an increase of the settling velocity. It can also be observed from Figure 4 that the settling velocity of $u$ is significantly greater than the settling velocities of either $v$ or $w$. The effect of the boundary of the settlement area is negligible. Experimental studies were also conducted on the flocculation of cohesive sand suspensions [29]. The settling velocities of the flocs in those experiments were $0.003 \sim 0.011 \mathrm{~m} \cdot \mathrm{s}^{-1}$ for particles whose concentration is $5 \mathrm{~g} / \mathrm{L}$ and $0.005 \sim 0.015 \mathrm{~m} \cdot \mathrm{s}^{-1}$ for particles whose concentration is $15 \mathrm{~g} / \mathrm{L}$, while the calculated settling velocity used in this study is $0.0038 \sim 0.012 \mathrm{~m} \cdot \mathrm{s}^{-1}$ in $15 \mathrm{~s} \sim 30 \mathrm{~s}$ (Figure 5). The calculated data is much closer to the experimental results.

For the variation of the curve in $0 \sim 15 \mathrm{~s}$, some authors $[40,41]$ believe that an uneven distribution of the shear rate is the main reason for the decrease of floc size. Selomulya et al. [20] suggest that size reduction is caused by the irregular and porous structure of flocs, making their structures more compact. The settling velocity is a function of size and 


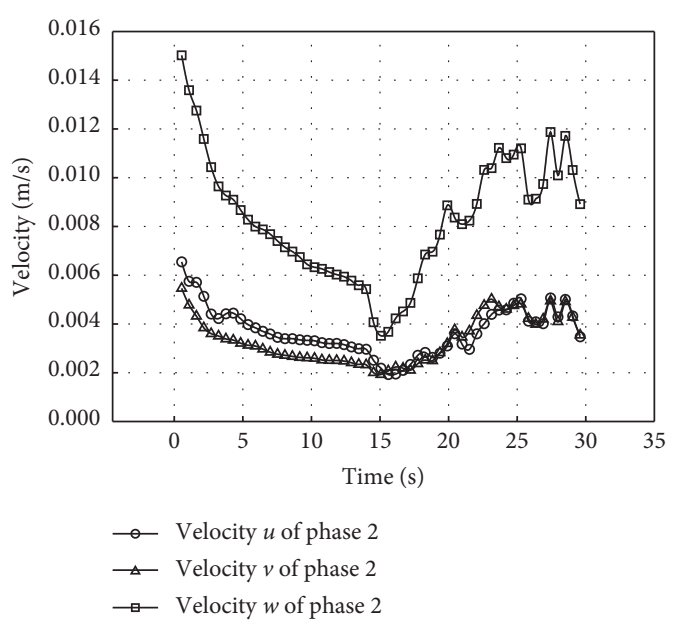

(a)

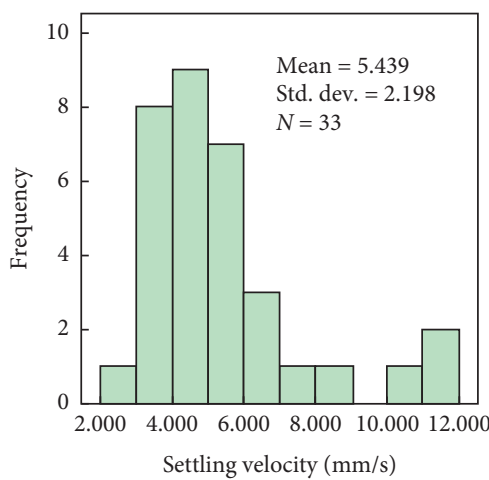

(b)

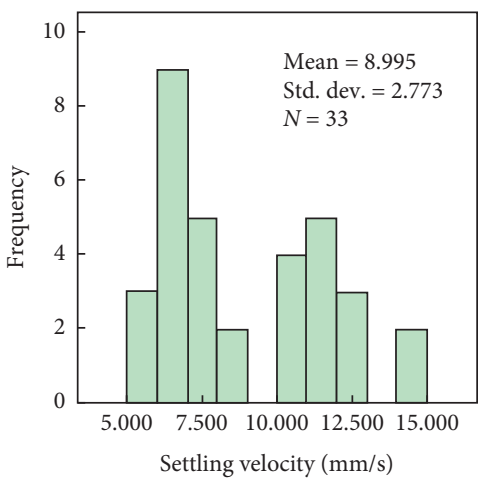

(c)

FIGURE 5: Settling velocities of particle or floc in model and experiments. (a) Time series of the settling velocities, phase 2 represents particles or flocs. $u$ is the direction of settlement; $v$ and $w$ are the radial directions perpendicular to $u$. (b) Statistics of the settling velocities in experiments when the particle concentration in suspension is $5 \mathrm{~g} / \mathrm{L}$. (c) Statistics of the settling velocities in experiments when the particle concentration in suspension is $15 \mathrm{~g} / \mathrm{L}$. (a) Model. (b) Experiments (particle concentration=5g/L). (c) Experiments (particle concentration $=15 \mathrm{~g} / \mathrm{L})$.
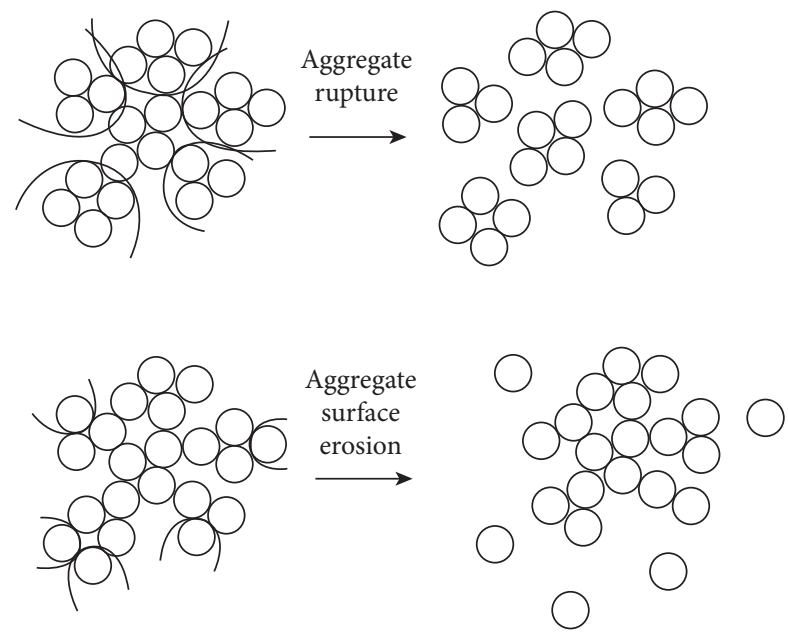

FIGURE 6: Mechanisms of different breakage modes of flocs. In the case of an aggregate rupture, both size and the perimeter change significantly. In the case of aggregate surface erosion, only the perimeter changes, and size remains almost constant.

density, and they have the same change law. We believe that aggregate rupture was the main reason for the curve decreasing in $0 \sim 15 \mathrm{~s}$, while aggregate surface erosion was the main reason for the curve fluctuation in 25 30 s, as shown in Figure 6. In the early phase, due to the aggregate rupture, the number of flocs increased, but the size decreased. On the contrary, in the later phase due to the aggregate surface erosion, the size of floc increased significantly [42]. The results presented in this paper confirm both hypotheses.

\section{Conclusions}

PBM was proven to be a more advanced model that is capable of approximating flocculation and sedimentation of particles better than previous versions. In contrast to the DLA or DLCCA model, the PBM can simultaneously simulate both the aggregation and breakage processes between microflocs and macroflocs with irregular shape. The presented results lead to the following conclusions:

(1) Particles, microflocs, and macroflocs are the three important states during the process of flocculation and sedimentation. This process is a dynamic and nonlinear process of aggregation, breakage, reaggregation, and rebreakage.

(2) There are three stages in the process of flocculation and sedimentation corresponding to the three above states. Shear effect focuses on the decrease of floc size, while differential settling influences the increase of floc size. Eventually, the equilibrium phase appears in which the breakage rate is equal to the aggregation rate.

(3) The process of flocculation and sedimentation can be reasonably described by aggregate rupture and aggregate surface erosion. They are two different mechanisms important for the settling velocity decreasing in the early stage and fluctuating in the late stage.

Finally, CFD-PBM is an effective method to study the dynamics of flocs and their influence on flocculation and sedimentation, in order to not only gain a deeper understanding of flocculation dynamics, but also to improve the theory of sediment movement.

\section{Nomenclature}

$\nabla:$

$S_{q}: \quad$ source item

$\alpha_{q}: \quad \quad$ volume fraction of phase $q$ 


\begin{tabular}{|c|c|}
\hline$\rho_{q}:$ & density of phase $q$ \\
\hline$\vec{v}_{q}:$ & velocity of phase $q$ \\
\hline$\dot{m}_{p q}:$ & mass transfer within phase $p$ to $q$ \\
\hline$\dot{m}_{q p}:$ & mass transfer within phase $q$ to $p$ \\
\hline$\overline{\bar{\tau}}_{q}:$ & $q^{\text {th }}$ phase stress-strain tensor \\
\hline & external body force \\
\hline$\vec{F}_{\text {lift }, q}:$ & lift force \\
\hline$\vec{F}_{\mathrm{wl}, q}:$ & wall lubrication force \\
\hline$\vec{F}_{\mathrm{vm}, q}:$ & virtual mass force \\
\hline$\vec{F}_{\text {td. } q}:$ & turbulent dispersion force \\
\hline$\vec{R}_{p q}:$ & interaction force between phases \\
\hline$P:^{P(1}$ & pressure \\
\hline$\vec{v}_{p q}:$ & interphase velocity \\
\hline$\vec{g}:$ & gravity acceleration, $9.81 \mathrm{~m} \cdot \mathrm{s}^{-2}$. \\
\hline$k$ : & the turbulence kinetic energy \\
\hline$\varepsilon:$ & turbulent energy dissipation rate \\
\hline$G_{k}:$ & $\begin{array}{l}\text { generation of turbulence kinetic energy due to } \\
\text { the mean velocity gradients }\end{array}$ \\
\hline$G_{\mathrm{b}}:$ & $\begin{array}{l}\text { generation of turbulence kinetic energy due to } \\
\text { buoyancy. }\end{array}$ \\
\hline$Y_{\mathrm{M}}:$ & $\begin{array}{l}\text { contribution of the fluctuating dilatation in } \\
\text { compressible turbulence to the overall } \\
\text { dissipation rate }\end{array}$ \\
\hline $\begin{array}{l}C_{1 \varepsilon}, C_{2 \varepsilon} \\
C_{3 \varepsilon}:\end{array}$ & constants, $1.44,1.92,0.09$ \\
\hline$\sigma_{k}:$ & turbulent Prandtl numbers for $k, 1.0$. \\
\hline$\sigma_{\varepsilon}:$ & turbulent Prandtl numbers for $\varepsilon, 1.3$ \\
\hline $\begin{array}{l}n(V, t): \\
\vec{u}:\end{array}$ & $\begin{array}{l}\text { number density of particles of volume } V \text { at time } t \\
\text { particle velocity }\end{array}$ \\
\hline$G:$ & the linear growth rate \\
\hline$B_{\mathrm{ag}}:$ & birth rate of aggregation \\
\hline$D_{\mathrm{ag}}$ : & death rate of aggregation \\
\hline$B_{\mathrm{br}}:$ & birth rate of breakage \\
\hline$D_{\text {br }}:$ & death rate of breakage \\
\hline$V^{\prime}:$ & particle volume \\
\hline$V:$ & floc volume \\
\hline$N:$ & number of particles \\
\hline
\end{tabular}

\section{Data Availability}

The model description and Figure 2 used to support the findings of this study were supplied by Northwest A\&F University under license and so cannot be made freely available. Requests for access to these data should be made to Professor Zhang Gengguang with email zgg@64.com. The data of Figures 3-5 used to support the findings of this study may be released upon application to the Northwest A\&F University, who can be contacted at zgg@64.com.

\section{Conflicts of Interest}

The authors declare no conflicts of interest.

\section{Authors' Contributions}

Z. P. S. and G. G. Z. performed conceptualization and methodology. Y. Z. Z., G. L. P., and Z. P. S performed investigation and date collection. $Z$. P. S wrote the original draft. G. G. Z and T. T. H reviewed and edited the draft. G. G. $Z$ supervised the study. G. G. Zhang and Z. P. Shi were responsible for funding acquisition.

\section{Acknowledgments}

The authors thanks Prof. Onyx W. H. Wai from the civil and environmental engineering department of the Hong Kong Polytechnic University for his kind advice which helped us prepare a better manuscript. This work was supported by the Jiangsu Overseas Visiting Scholar Program for University Prominent Young \& Middle-aged Teachers and Presidents (2018), National Natural Science Foundation of China (grant no. 51879227), Qing Lan Project (2016), and Science and Technology Project of Department of Housing and UrbanRural Development of Jiangsu province (grant no. 2016ZD80).

\section{References}

[1] R. L. Xia, G. L. Yang, and L. S. Liu, "Simulation for fine sediment flocculating settlement in flowing water and its influential factors," Engineering Journal of Wuhan University, vol. 46, no. 2, pp. 149-153, 2013.

[2] T. S. Yang, F. Li, and C. H. Lian, "Computer simulation of flocculation growth for cohesive sediment in still water," Journal of Sediment Research, vol. 4, pp. 14-20, 2005.

[3] A. J. Manning, P. L. Friend, N. Prowse, and C. L. Amos, "Estuarine mud flocculation properties determined using an annular mini-flume and the LabSFLOC system," Continental Shelf Research, vol. 27, no. 8, pp. 1080-1095, 2007.

[4] D. Bouyer, A. Line, and A. Cockx, "Experimental analysis of floc size distribution and hydrodynamics in a jar-test," Chemical Engineering Research \& Design, vol. 79, no. 8, pp. 1017-1024, 2001.

[5] B. G. Li, D. Eisma, Q. C. Xie, J. Kalf, Y. Li, and X. Xia, "Concentration, clay mineral composition and Coulter counter size distribution of suspended sediment in the turbidity maximum of the Jiaojiang river estuary, Zhejiang, China," Journal of Sea Research, vol. 42, no. 2, pp. 105-116, 1999.

[6] D. Orange, A. García-García, T. Lorenson et al., "Shallow gas and flood deposition on the Po Delta," Marine Geology, vol. 222-223, pp. 159-177, 2005.

[7] T. A. Witten and L. M. Sander, "Diffusion-limited aggregation, a kinetic critical phenomenon," Physical Review Letters, vol. 47, no. 19, pp. 1400-1403, 1981.

[8] P. K. Jin, X. C. Wang, and K. Guo, "DLA Simulation of fractal flocs and calculation of fractal dimension," Environmental Chemisitry, vol. 26, no. 1, pp. 5-9, 2007.

[9] Z. Y. Qin, Z. M. Qiu, and W. Y. Chen, "Simulation on flocs using three dimensional DLA model," Journal of Nanchang University, vol. 32, no. 2, pp. 122-126, 2010.

[10] D. J. Liu, W. G. Zhou, X. Song, and Z. M. Qiu, "Fractal simulation of flocculation processes using a diffusion-limited aggregation model," Fractal and Fractional, vol. 1, no. 12, pp. 1-14, 2017.

[11] P. Meakin, "Formation of fractal clusters and networks by irreversible diffusion-limited aggregation," Physical Review Letters, vol. 51, no. 13, pp. 1119-1122, 1983.

[12] J. C. Gimel, D. Durand, and T. Nicolai, "Transition between flocculation and percolation of a diffusion-limited cluster- 
cluster aggregation process using three-dimensional Monte Carlo simulation," Physical Review B, vol. 51, no. 17, pp. 11348-11357, 1995.

[13] J. Zhang and Q. Zhang, "Direct simulation of drag force on fractal flocs during settling," Journal of Coastal Research, vol. 73, no. 1, pp. 753-757, 2015.

[14] C. A. Biggs and P. A. Lant, "Modelling activated sludge flocculation using population balances," Powder Technology, vol. 124, no. 3, pp. 201-211, 2002.

[15] P. Garrido, R. Burgos, F. Concha, and R. Bürger, "Software for the design and simulation of gravity thickeners," Minerals Engineering, vol. 16, no. 2, pp. 85-92, 2003.

[16] Y. Liao, D. Lucas, E. Krepper, and M. Schmidtke, "Development of a generalized coalescence and breakup closure for the inhomogeneous MUSIG model," Nuclear Engineering and Design, vol. 241, no. 4, pp. 1024-1033, 2011.

[17] I. Nopens, D. Beheydt, and P. A. Vanrolleghem, "Comparison and pitfalls of different discretised solution methods for population balance models: a simulation study," Computers \& Chemical Engineering, vol. 29, no. 2, pp. 367-377, 2005.

[18] M. Petitti, M. Vanni, D. L. Marchisio, A. Buffo, and F. Podenzani, "Simulation of coalescence, break-up and mass transfer in a gas-liquid stirred tank with CQMOM," Chemical Engineering Journal, vol. 228, pp. 1182-1194, 2013.

[19] O. P. Prat and J. J. Ducoste, "Modeling spatial distribution of floc size in turbulent processes using the quadrature method of moment and computational fluid dynamics," Chemical Engineering Science, vol. 61, no. 1, pp. 75-86, 2006.

[20] C. Selomulya, G. Bushell, R. Amal, and T. D. Waite, "Understanding the role of restructuring in flocculation: the application of a population balance model," Chemical Engineering Science, vol. 58, no. 2, pp. 327-338, 2003.

[21] L. F. L. R. Silva, R. B. Damian, and P. L. C. Lage, "Implementation and analysis of numerical solution of the population balance equation in CFD packages," Computers \& Chemical Engineering, vol. 32, no. 12, pp. 2933-2945, 2008.

[22] D. N. Thomas, S. J. Judd, and N. Fawcett, "Flocculation modelling: a review," Water Research, vol. 33, no. 7, pp. 1579-1592, 1999.

[23] A. Amokrane, S. Maass, F. Lamadie, F. Puel, and S. Charton, "On droplets size distribution in a pulsed column. Part I: in-situ measurements and corresponding CFD-PBE simulations," Chemical Engineering Journal, vol. 296, pp. 366-376, 2016.

[24] M. Golzarijalal, F. Z. Ashtiani, and B. Dabir, "Modeling of microalgal shear-induced flocculation and sedimentation using a coupled CFD-population balance approach," Biotechnology Progress, vol. 34, no. 1, pp. 160-174, 2018.

[25] Z. L. Li, "Population balance model for the flocculation process: a research review," Journal of Chongqing University of Education, vol. 26, no. 3, pp. 8-12, 2013.

[26] Y. Zhou, T. Lei, Z. M. Zheng, G. X. Zheng, J. J. Xu et al., "Flocculation reaction model based on population balance principle," China Water and Wastewater, vol. 30, no. 21, pp. 54-57, 2014.

[27] P. Somasundaran and V. Runkana, "Modeling flocculation of colloidal mineral suspensions using population balances," International Journal of Mineral Processing, vol. 72, no. 1-4, pp. 33-55, 2003.

[28] Z.-e. Ruan, C.-p. Li, and C. Shi, "Numerical simulation of flocculation and settling behavior of whole-tailings particles in deep-cone thickener," Journal of Central South University, vol. 23, no. 3, pp. 740-749, 2016.

[29] Z. P. Shi, G. G. Zhang, J. C. Liu, and T. T. He, "Predicting the floc characteristics and settling velocity of flocs under various polyacrylamide concentration treatments," Taiwan Water Conservancy, vol. 64, no. 2, pp. 77-90, 2016.

[30] A. X. Fan, N. J. Turro, and P. Somasundaran, "A study of dual polymer flocculation," Colloids and Surfaces A-Physicochemical and Engineering Aspects, vol. 162, no. 1-3, pp. 141$148,2000$.

[31] A. J. Manning and K. R. Dyer, "Mass settling flux of fine sediments in Northern European estuaries: measurements and predictions," Marine Geology, vol. 245, no. 1-4, pp. 107-122, 2007.

[32] B. J. Lee, E. Toorman, F. J. Molz, and J. Wang, "A two-class population balance equation yielding bimodal flocculation of marine or estuarine sediments," Water Research, vol. 45, no. 5, pp. 2131-2145, 2011.

[33] R. Gregory and T. F. Zable, "Sedimentation and flotation," in Water Quality and Treatment: A Handbook of Community Water Supplies, McGraw-Hill, New York, NY, USA, 1999.

[34] V. Vahid and J. B. P. Soares, "Monitoring polymer flocculation in oil sands tailings: a population balance model approach," Chemical Engineering Journal, vol. 346, pp. 447-457, 2018.

[35] M. J. Hounslow, R. L. Ryall, and V. R. Marshall, "A discretized population balance for nucleation, growth, and aggregation," AIChE Journal, vol. 34, no. 11, pp. 1821-1832, 1988.

[36] R. I. Jeldres, F. Concha, and P. G. Toledo, "Population balance modelling of particle flocculation with attention to aggregate restructuring and permeability," Advances in Colloid and Interface Science, vol. 224, pp. 62-71, 2015.

[37] A. R. Heath, P. A. Bahri, P. D. Fawell, and J. B. Farrow, "Polymer flocculation of calcite: population balance model," AIChE Journal, vol. 52, no. 5, pp. 1641-1653, 2006.

[38] G. J. Hong and T. S. Yang, "3D simulation of flocculation settling of cohesive fine sediment," Journal of Hydraulic Engineering, vol. 37, no. 2, pp. 172-177, 2006.

[39] D. M. Li, T. G. Jing, Z. S. Li, and W. C. Tan, "The effect of concentration of high molecular weight flocculants on fractal structures of bridging flocculated aggregates for sediments," Journal of Guangdong University of Technology, vol. 23, no. 3, pp. 40-45, 2006.

[40] C. Selomulya, R. Amal, G. Bushell, and T. D. Waite, "Evidence of shear rate dependence on restructuring and breakup of latex aggregates," Journal of Colloid and Interface Science, vol. 236, no. 1, pp. 67-77, 2001.

[41] P. T. Spicer and S. E. Pratsinis, "Shear-induced flocculation: the evolution of floc structure and the shape of the size distribution at steady state," Water Research, vol. 30, no. 5, pp. 1049-1056, 1996.

[42] P. Bubakova, M. Pivokonsky, and P. Filip, "Effect of shear rate on aggregate size and structure in the process of aggregation and at steady state," Powder Technology, vol. 235, pp. 540-549, 2013. 

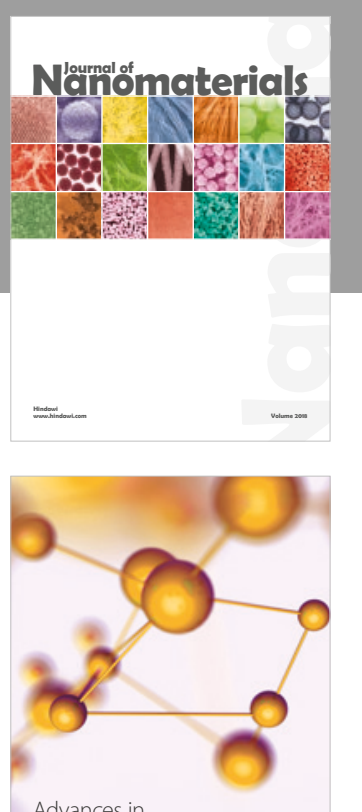

Physical Chemistry
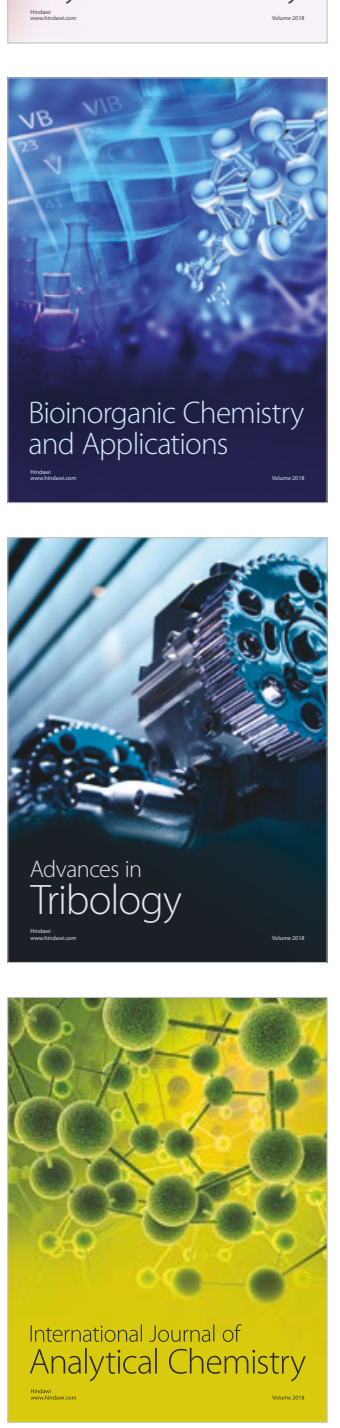

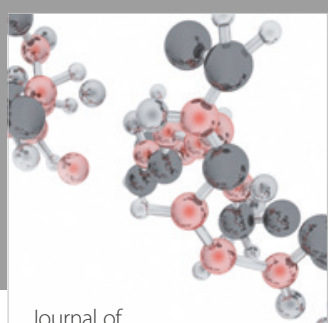

Analytical Methods

in Chemistry

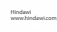

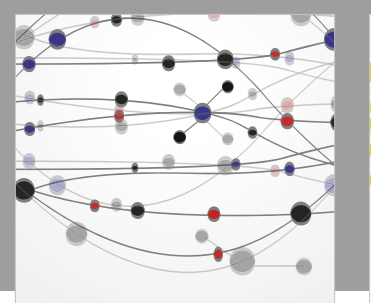

The Scientific World Journal

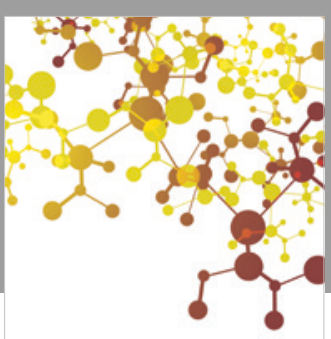

Journal of

Applied Chemistry
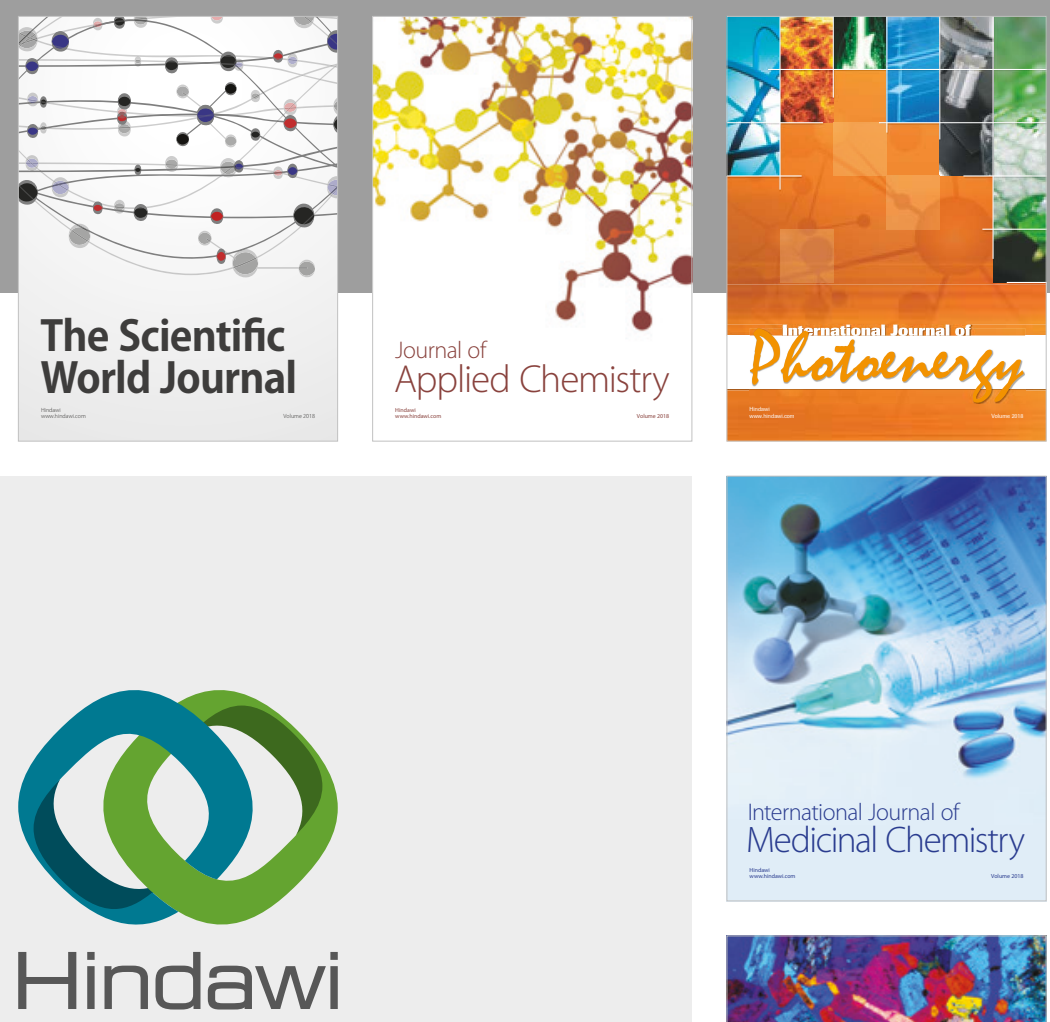

Submit your manuscripts at

www.hindawi.com
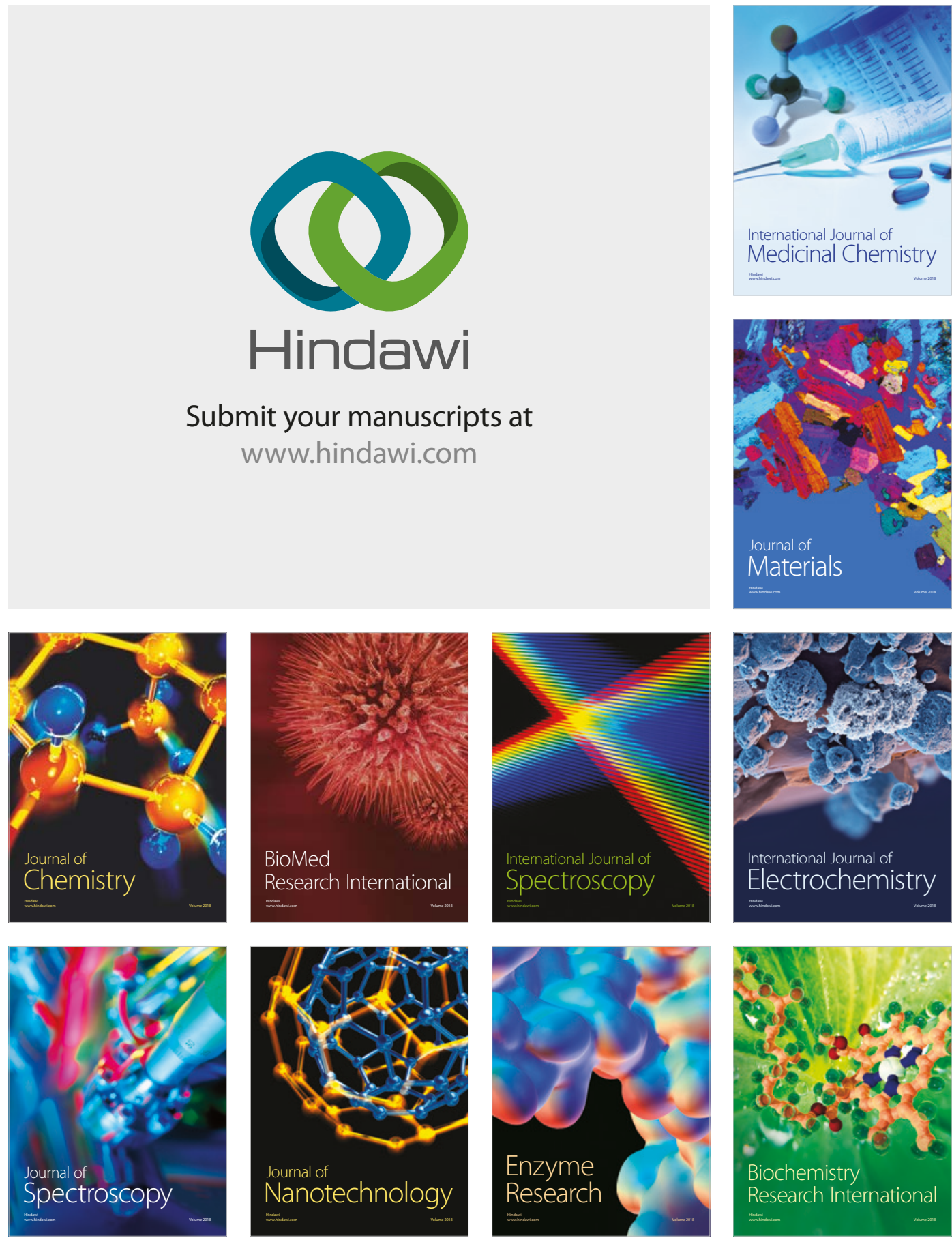
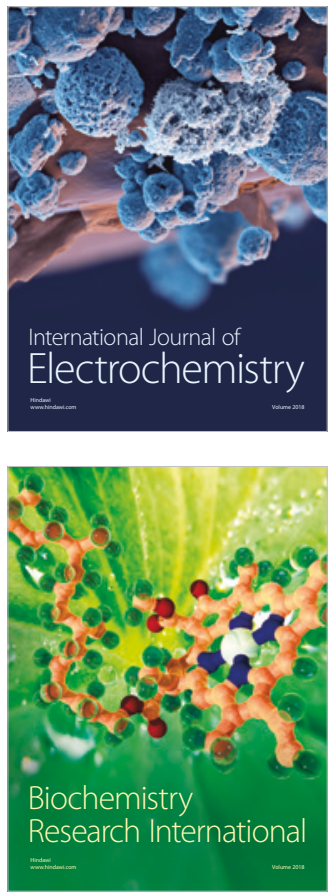